\title{
Mast cells in human airways: the culprit?
}

\author{
Jonas S. Erjefält
}

Affiliation: Experimental Medical Science, Unit of Airway Inflammation, Lund University, Lund, Sweden.

Correspondence: Jonas S. Erjefält, Experimental Medical Science, Unit of Airway Inflammation, Lund University, BMC D12, Lund S-22184, Sweden. E-mail: Jonas.Erjefaltamed.lu.se

ABSTRACT By virtue of their undisputed role in allergy, the study of airway mast cells has focused on nasal and bronchial mast cells and their involvement in allergic rhinitis and asthma. However, recent mechanistic and human studies suggest that peripheral mast cells also have an important role in asthma, as well as chronic obstructive pulmonary disease, respiratory infections and lung fibrosis. Pathogenic roles include immune-modulatory, pro-inflammatory and pro-fibrotic activities. Importantly, mast cells also actively downregulate inflammation and participate in the defence against respiratory infections. Another complicating factor is the notorious mast cell heterogeneity, where each anatomical compartment of the lung harbours site-specific mast cell populations.

Alveolar mast cells stand out as they lack the cardinal expression of the high affinity IgE receptor. Supporting the emerging concept of alveolar inflammation in asthma, alveolar mast cells shift to a highly FceRI-expressing phenotype in uncontrolled asthma. Site-specific and disease-associated mast cell changes have also recently been described in most other inflammatory conditions of the lung. Thus, in the exploration of new anti-mast cell treatment strategies the search has widened to include the lung periphery and the delicate task of identifying which of the countless potential roles are the critical disease modifying ones in a given clinical situation.

@ERSpublications

Mast cells have recently been assigned new roles in all inflammatory conditions and anatomic regions of the lung http://ow.ly/zoPnf

\section{Introduction}

The mast cell, which was first described in 1878 by Paul Ehrlich, is a long-lived, multifunctional immune cell characterised by large mediator-laden granules. They are resident in most tissues of the body, with a particularly high density in tissues facing an external milieu, e.g. the airways. This strategic position and the large quantities of pre-formed granule mediators allow mast cells to respond rapidly to external triggers and kick-start an inflammatory response $[1,2]$. To avoid this response getting out of control, mast cells also have the molecular machinery to actively inhibit inflammatory responses [3].

Although mast cells were discovered more than a century ago, apart from their well-established role in IgEinduced degranulation $[4,5]$, many of their functions remain enigmatic. Nonetheless, it is clear that with their multi-potent capacity mast cells have many important roles in respiratory diseases that go far beyond initiating allergic responses. Indeed, more recent research has implicated mast cell functions in the immunopathology of chronic obstructive pulmonary disease (COPD) [6,7], fibrotic lung diseases [8-11] and respiratory infections $[12,13]$. A major challenge of today's mast cell research is how to separate the

For editorial comments see page 275 .

Received: June 112014 | Accepted after revision: July 152014

Support statement: Funding support for research in this field was received from the Swedish Research Council and the Swedish Heart and Lung Foundation.

Conflict of interest: None declared.

Provenance: Submitted article, peer reviewed.

Copyright CERS 2014. ERR articles are open access and distributed under the terms of the Creative Commons Attribution Non-Commercial Licence 4.0. 
protective and beneficial roles from those that are harmful, an exercise that is challenging but instrumental for the design of effective and novel anti-mast cell treatment strategies.

\section{Established and emerging roles for mast cells in respiratory disorders}

A key physiological role of mast cells is to rapidly recognise pathogens and mount an appropriate immune response. The most established and well-studied involvement of mast cells is their accidental activation in allergy where cross-linking of surface-bound IgE leads to rapid degranulation, mediator release (e.g. histamine) and manifestation of an acute phase allergic reaction [1,14]. Apart from the acute airway constriction, one hugely important tissue reaction is plasma extravasation [15, 16]. Within seconds, released histamine and serotonin evoke endothelial gap formation in post-capillary venules and extravasation of bulk plasma into the airway wall and lumen, resulting in airway oedema and increased luminal plug formation [15]. Another important, but often neglected, aspect of plasma extravasation is its profound immunological effect. During the immediate extravasation the extracellular matrix and extracellular epithelial spaces will be soaked with plasma proteins that have potent immunological and cytokinemodulating properties, which will greatly facilitate the subsequent leukocyte recruitment and development of a cellular inflammation $[15,16]$.

The immediate mast cell degranulation is followed by a fast $(20-40 \mathrm{~min})$ de novo production of potent leukotrienes and prostaglandins that further aggravate the response. Apart from the classical anaphylactic mediators and proteases, mast cell degranulation also liberates a large number of pre-stored or de novo synthetised cytokines (e.g. tumour necrosis factor (TNF)- $\alpha$, interleukin (IL)-4, IL-6, IL-13 and IL-17) [2, 14]. These cytokines can contribute to both the initiation of the subsequent late phase reaction as well as maintaining chronic inflammation [17-19]. Another mechanism contributing to chronicity is an amplification loop where elevated levels of $\operatorname{IgE}$ in sensitised patients increase the FceRI expression and survival of mast cells. This boosts the mast cell capacity of the IgE-mediated release of mediators, which promote further expanded IgE production by stimulating FceRI-expressing dendritic cells and their activation of cognate T- and B-cells [14].

IgE-mediated mast cell degranulation is such an established hallmark of allergic respiratory conditions that it has overshadowed many of the other mast cell activities taking place in inflammatory airway diseases. Nonetheless, mast cells are active players in a broad range of other basic immunological mechanisms, ranging from leukocyte recruitment and general immune orchestration to tissue repair and remodelling (these aspects have been reviewed previously $[12,18,20]$ ). Mast cells also have an important task as sentinels of infection. To sense invading microbes mast cells express a variety of receptors for pathogenassociated molecular patterns such as Toll-like receptors (1 to 9), Nod-like receptors and Rig-I family receptors [21]. Activation of these stimulates the release of IL-1 $\beta$, TNF, IL-6, interferons, CCL2 and CCL5 $[12,22-24]$. The role of mast cells in the defence against microbes is not only relevant for infectious diseases; important host defence roles for mast cells may also occur in chronically colonised cystic fibrosis (CF) patients, as well as in asthma and COPD where respiratory infections are a major cause of disease exacerbation [25-27].

Apart from their pro-inflammatory actions, mast cells have an impressive capacity to downregulate immunological responses; for example by releasing the anti-inflammatory cytokine IL-10 [28]. Another anti-inflammatory action is through the capacity of mast cell granule proteases to degrade and neutralise key cytokines, such as TNF- $\alpha$, IL-4, IL-13 and IL-33 [29, 30]. Thus, mast cells act as ever-present local immune modulators with the capacity to coordinate the delicate balance between pro- and antiinflammatory responses. A good example of this double nature of mast cells is their involvement in creating a T-helper (Th)2 response (fig. 1). The production of Th2 cytokines (IL-4, IL-5 and IL-13) may not only be implemented by Th2 lymphocytes, but also by the newly discovered type 2 innate lymphoid cells (ILC2), as well from mast cells themselves. Mast cells may further boost the response by releasing Th2 lymphocyteand ILC2-stimulating factors [31]. Importantly, mast cells also have efficient machinery to dampen the response via active degradation or steric neutralisation of Th2 cytokines (fig. 1). Considering the multitude of reported mast cell functions and the fact that mast cells are constantly present at the site of any inflammation, it is likely that conceptually similar "yin and yang" functions of mast cells take place in most other types of immune responses. A better understanding of the kinetics of this balance and relative weight of the pro- and anti-inflammatory actions of mast cells is critical in order to define when and how mast cells can be targeted pharmacologically.

\section{Mast cell heterogeneity and anatomical site-specific subtypes}

A key secret to how mast cells can handle their vast array of different functions is the existence of "specialised" mast cell subtypes. Indeed, it has long been recognised that although all tissue mast cells share 


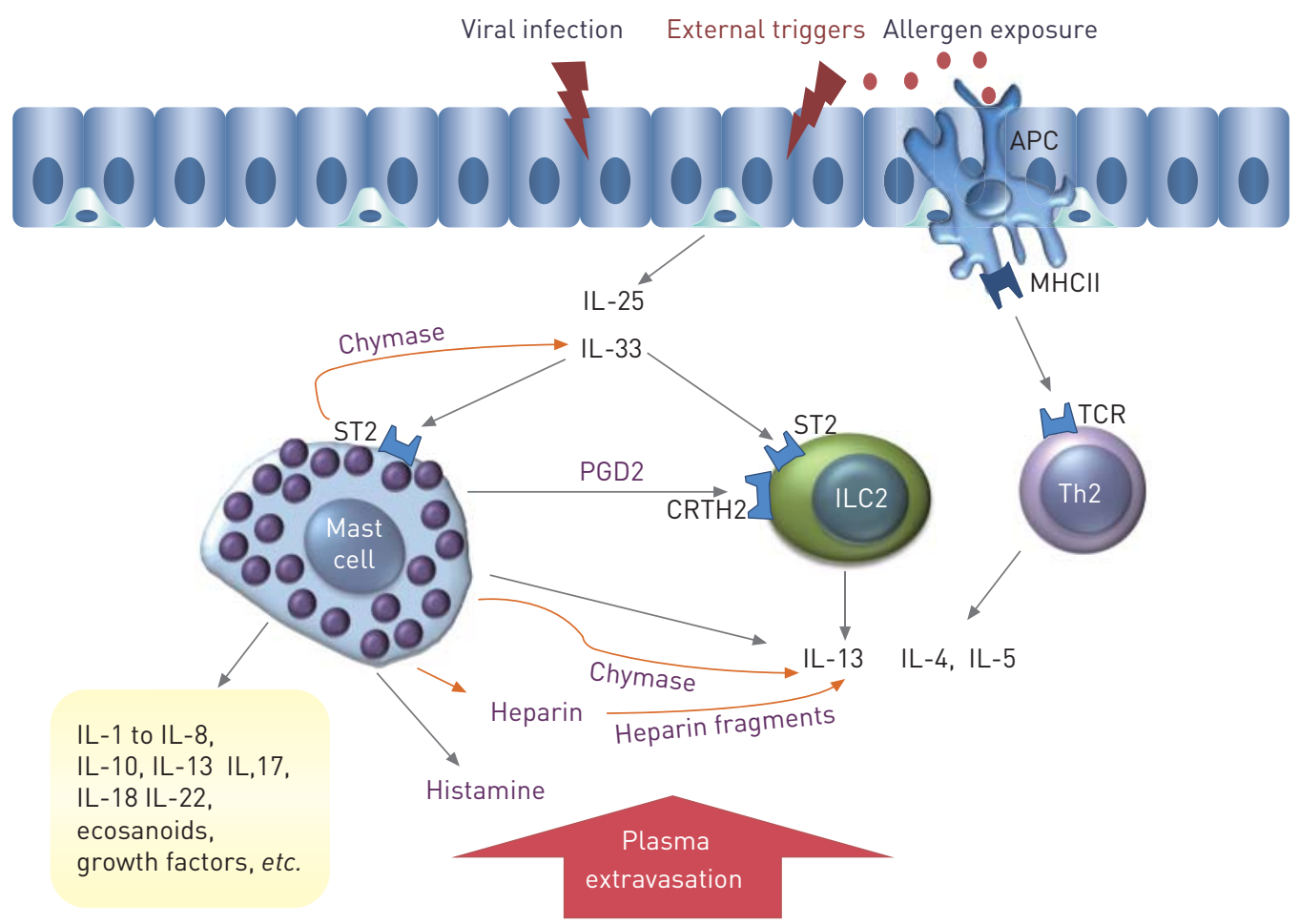

FIGURE 1 Using a T-helper (Th)2 response as an example this schematic diagram exemplifies a general principle of mast cells, namely to control immunological reactions by both promoting and actively dampening the response. Th2 cytokines such as interleukin (IL)-4, IL- 5 and IL-13 are classically produced by activated $\mathrm{CD}^{+} \mathrm{Th} 2$ cells. Alternatively, Th2 cytokines can also be produced by the newly discovered type 2 innate lymphoid cells (ILC2), whose activation is triggered by IL-25 and IL-33 released from structural cells. Mast cells, which are also activated by IL-33, produce prostaglandin (PG)D2 and leukotriene D4 that act as potent ILC2 activators. Importantly, mast cells can also directly produce Th2 cytokines. To control the response mast cells have molecular machinery to actively downregulate the situation (orange arrows). Among the mechanisms for this are proteolytic degradation of IL-33 and Th2 cytokines, as well as cytokine binding/ neutralisation by heparin fragments and extravasated cytokine-binding proteins. APC: antigen presenting cell; MHC: major histocompatibility complex; TCR: T-cell receptor; CRTH2: chemoattractant receptor-homologous molecule expressed on Th2 cells; ST2: suppression of tumorigenicity-2.

many characteristics, they do not represent a homogenous population. This heterogeneity, which involves differences in morphology, mediator content and response to external stimuli, constitutes a major challenge for understanding the role of mast cells in health and disease.

The first robust classification of mast cells into subtypes was originally made in rodents [32, 33]. Based on distinct staining characteristics and anatomical location, rodent mast cells could be divided into connective tissue mast cells and mucosal mast cells. It was soon discovered that these populations differed, not only in their tissue distribution, but also in morphology, granule content and function [33, 34]. The mast cell heterogeneity in humans is at least as multifaceted. One major type is referred to as MCTC since they express both tryptase and chymase (corresponds to the connective tissue mast cell population in rodents). The other main subpopulation lacks chymase but contains tryptase and is consequently known as MCT, (corresponding to rodent mucosal mast cells) [1,35].

It has now become increasingly clear that mast cell heterogeneity in humans goes beyond the division into MCT and MCTC subpopulations. The respiratory system may serve as an illustration of this as different anatomical regions and microenvironments of the lung create an expanded "site-specific" heterogeneity (figs 2 and 3) [41]. In support of this, direct comparisons between human lung mast cells in multiple anatomical lung compartments have suggested that each of the MCT and MCTC populations can be further differentiated based on their size, shape and molecular expression profiles [41, 42]. One intriguing observation was that the alveolar mast cells, in contrast to mast cells in the rest of the body, lacked FceRI expression [41]. Interestingly, in contrast to the intensively studied rodents, the alveolar parenchyma in the human lung is richly populated by mast cells [41, 43, 44]. Thus, alveolar mast cells in humans represent a large but poorly recognised mast cell population in the lung. The physiological function of alveolar mast cells is still a mystery. For example, none of the classical mast cell effector functions executed in allergy and asthma take place in the alveolar compartment; there are no smooth muscles to contract, no glands to stimulate, and induction of an alveolar plasma extravasation would be fatal. Hence, a definition of the 


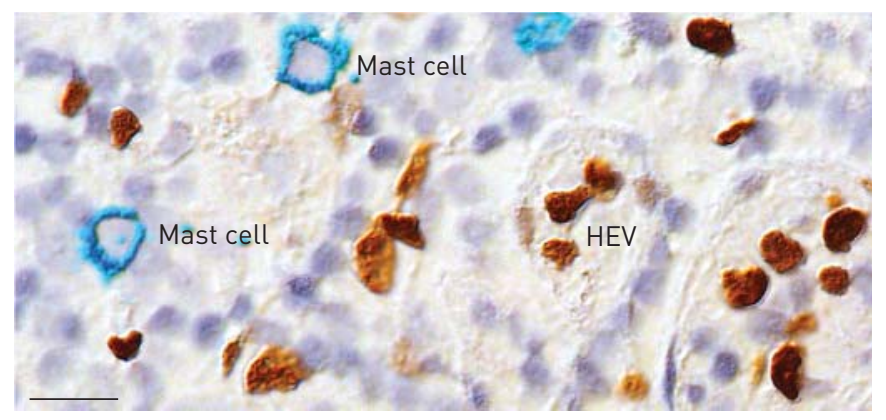

FIGURE 2 Apart from their well-established presence in the conducting airways, mast cells in the human respiratory system are also abundant in other key compartments such as the alveolar parenchyma or, as illustrated here, respiratory lymphoid tissue. Immunohistochemical staining of lymphoid mast cells (blue stained tryptase) can be seen together with abundant structural cells containing the potent mast cell activator interleukin-33 (brown stain). HEV: high endothelial venule. Scale bar $=20 \mu \mathrm{m}$. Image courtesy of J.S. Erjefält and P. Siddhuraj (Unit of Airway Inflammation, Lund University, Lund, Sweden).

biological and pathological role of alveolar mast cells, which actually represent the largest mast cell population in the human lung, seems warranted. Among the candidate functions are homeostatic regulation of the pulmonary vasculature, alveolar defence or distal orchestration of the immune response in the lung. Alveolar mast cells may also play a role in asthma.

\section{Alveolar mast cells: a new player in inflammatory airway diseases}

Asthma is traditionally regarded, and pharmacologically treated, as a disease of the central airways. Today, it is clear that asthma is a heterogeneous disease that can be divided into inflammatory phenotypes [45-49]. Another less recognised dimension of asthma heterogeneity relates to the anatomical distribution of the

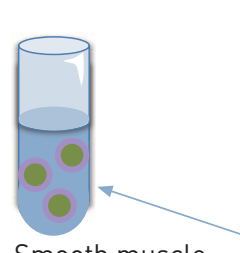

Smooth muscle mast cells
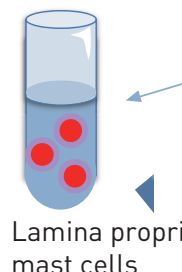
mast cells

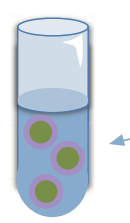

Lymph node mast cells
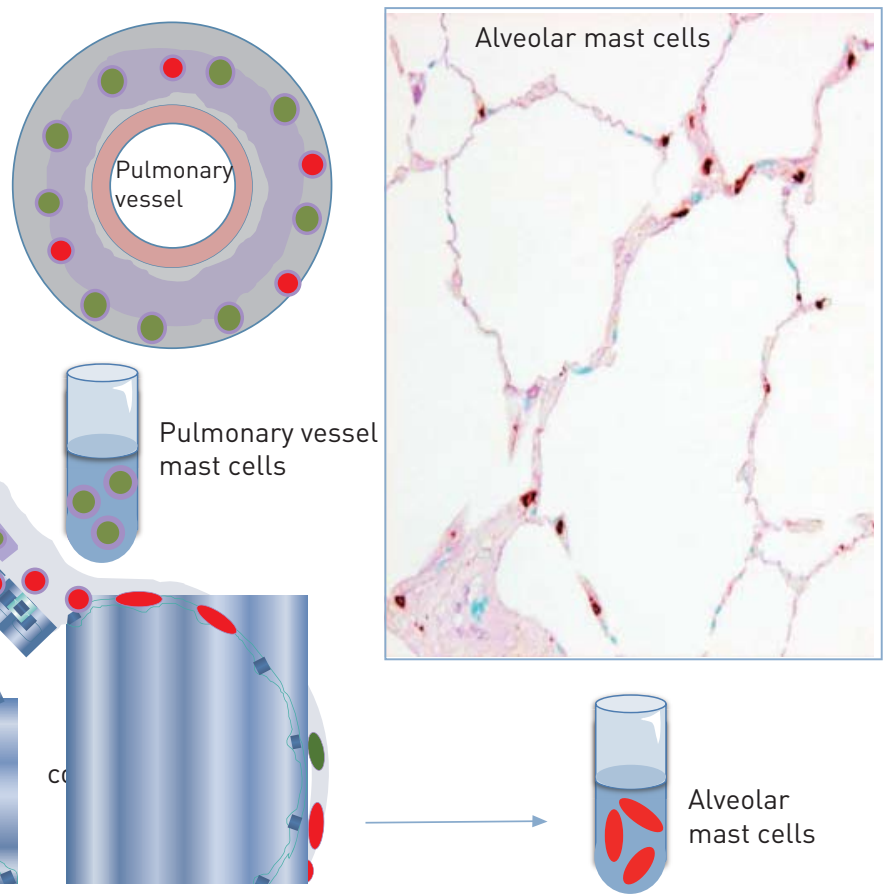

Alveolar

mast cells

FIGURE 3 Schematic image of mast cell heterogeneity in a healthy human lung. The unique molecular environments in the different anatomical compartments

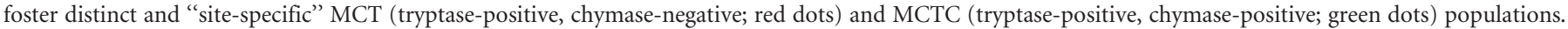

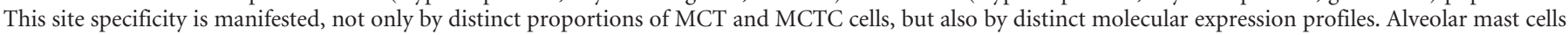
represent a large but, at present, poorly studied mast cell pool that is unique as it lacks FceRI-expression and seems to have important roles in both asthma and

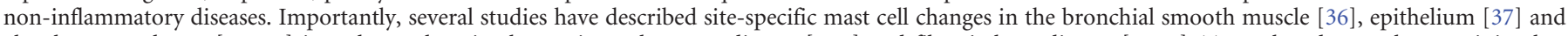
alveolar parenchyma $[38,39]$ in asthma, chronic obstructive pulmonary disease [6, 7] and fibrotic lung disease [9, 40]. Test tubes denote the remaining but important challenge to develop protocols for in vitro generation of mast cells that mimic defined site-specific MCT or MCTC populations. 
disease. Thus, in some patients the disease may be restricted to the central airways whereas in others there is distal lung involvement. Indeed, accumulated evidence from physiological and histological studies provides clear indications that inflammatory processes in asthma are also present in the most distal part of the lung [50-53]. However, the nature of this inflammation is, to a large extent, unknown. The few studies carried out to date point towards an increased alveolar infiltration of leukocytes and activation of parenchymal fibroblasts [54].

Interestingly, recent studies have also revealed dramatic alteration of alveolar mast cells in allergic asthma. In a unique study exploring bronchial and transbronchial biopsies in healthy controls and patients with atopic inhaled corticosteroid-treated uncontrolled asthma, it was recently shown in asthmatic lungs that the alveolar MCT and MCTC populations, which normally have low FceRI expression, expand and acquire an FceRI-expressing phenotype [38]. This phenomenon was paralleled by an equally robust upregulation of surface-bound IgE indicating that in allergic asthma, mast cells shift to a more allergen-responsive phenotype (importantly, this phenotype shift seems to be significantly lower in clinically controlled patients). A separate study showed that this phenomenon was also present in patients with mild inhaled corticosteroid-treated asthma, but not in patients with allergic rhinitis with no concomitant asthma [39]. Importantly, emergence of highly FceRI-expressing mast cells could not be seen in COPD, smoking controls, idiopathic pulmonary fibrosis (IPF) or CF (data not shown).

Altogether, from these findings it can be shown that a robust upregulation of FceRI-expression (and surface-bound $\operatorname{IgE}$ ) on alveolar mast cells is a novel disease-specific feature of atopic asthma. Recent further studies have revealed that the alveolar mast cell changes in allergic asthma are associated with a Th2-skewed alveolar cell profile, which correlates significantly with the degree of clinical control [55]. A potential link between distal inflammation and poor asthma control has important practical consequences. One example concerns medical treatment since current inhalation therapy does not target the alveolar region effectively. Some data indicate that improved control may be gained by more distal drug distribution [56]. Hence, it seems important to obtain further insight into the clinical benefit of pharmacological treatment of the distal lung in uncontrolled asthma and how this may affect key cells like alveolar mast cells and distal lymphocytes.

Alveolar mast cells are also likely to have important roles in several nonallergic disorders. In support of this, both MCT and MCTC populations are altered in COPD lungs where they upregulate markers of activation [6]. Similar to asthma, the "umbrella diagnosis" of COPD can be sub-divided into clinical and inflammatory disease phenotypes [57]. It is likely that the relative role of mast cells differs between these subtypes. As an indication of this, COPD patients that have centriacinar emphysema display a mast cell distribution pattern that differs from those with panlobular emphysema [7].

A mast cell link has also been suggested for fibrotic lung disorders, with several studies reporting increased numbers of mast cells $[8-10,40,58]$. The rational for mast cell involvement in IPF is strengthened by their capacity to produce a variety of pro-fibrotic factors and chemokines, which activate fibroblasts to increase extracellular matrix deposition. In support of this, the fibrotic lesions in IPF and CF have a very high content of infiltrating transforming growth factor- $\beta$-expressing MCTC mast cells [9].

\section{Future challenges in the search for improved in vitro mast cell models}

The broad heterogeneity of mast cells in humans inevitably raises questions regarding to what extent commonly used mast cell lines mimic the diversity present among mast cells in vivo. Common protocols for generating mast cell lines or purified mast cells have proven very useful, as reflected by their use in the pioneering work on molecular regulation and signalling in mast cells $[59,60]$. However, the situation gets more complicated when using in vitro mast cell experiments to study disease or organ-specific mast cell mechanisms. The magnitude of the in vivo heterogeneity suggests that it will be difficult, if not impossible, to produce a "one type fits all" in vitro phenotype. Instead, an attractive opportunity and a major challenge in the field would be to develop a panel of well-defined protocols producing distinct mast cell phenotypes with a defined resemblance to corresponding in vivo counterparts (fig. 2). The rapid development in multi cell-culture techniques and explant systems will likely aid development in this field.

\section{Emerging opportunities for decoding mast cell changes in humans}

The creation of more defined in vitro mast cell systems and the new generation of sophisticated mouse models for mast cell research will undoubtedly generate a new wave of exciting information [2]. In order to exploit this development it is crucial that the cell culture and animal research is matched by a focused exploration of what mast cells are actually doing in patients, either systemically or, perhaps more critically, inside the many compartments of the diseased tissue. Unfortunately, contrasting with the experimental animal situation, the current toolbox for assessing mast cells in humans is limited (table 1). In fact, apart from acute IgE-mediated degranulation, almost nothing is known regarding when and where in diseased 
patient tissues mast cells actually perform the myriad of the potentially disease-modifying functions postulated from animal models and experimental in vitro systems. One attractive approach to address this issue is through new improved technologies for advanced histological assessment of complex cell patterns. Until now histological studies have, for technical reasons, not included information on how alterations of tissue mast cells relate to the complexity of the complete immunological and histopathological profile, e.g. how they relate to tissue damage (and remodelling) and local infiltration patterns of the many other immune cells present in inflamed tissues. Exciting new possibilities will be offered by new "histomic" methods that can simultaneously visualise and quantify mast cells together with all major immune cell populations.

\section{Experience from human interventional studies}

As for all immune cells, the ultimate and direct proof of mast cell involvement in inflammatory airway diseases will come from clinical trials. The pharmaceutical industry has produced an impressive list of compounds for pharmacological targeting of mast cells or mast cell products (naturally most of them where developed for allergic disease) [46, 61, 62]. Whereas most of these are not specific to mast cells, some important conclusions can be drawn from interventional patient studies. The first "anti-mast cell" drugs to

\section{TABLE 1 Common markers for identifying and assessing human mast cells}

\section{Marker}

Other name
Comment

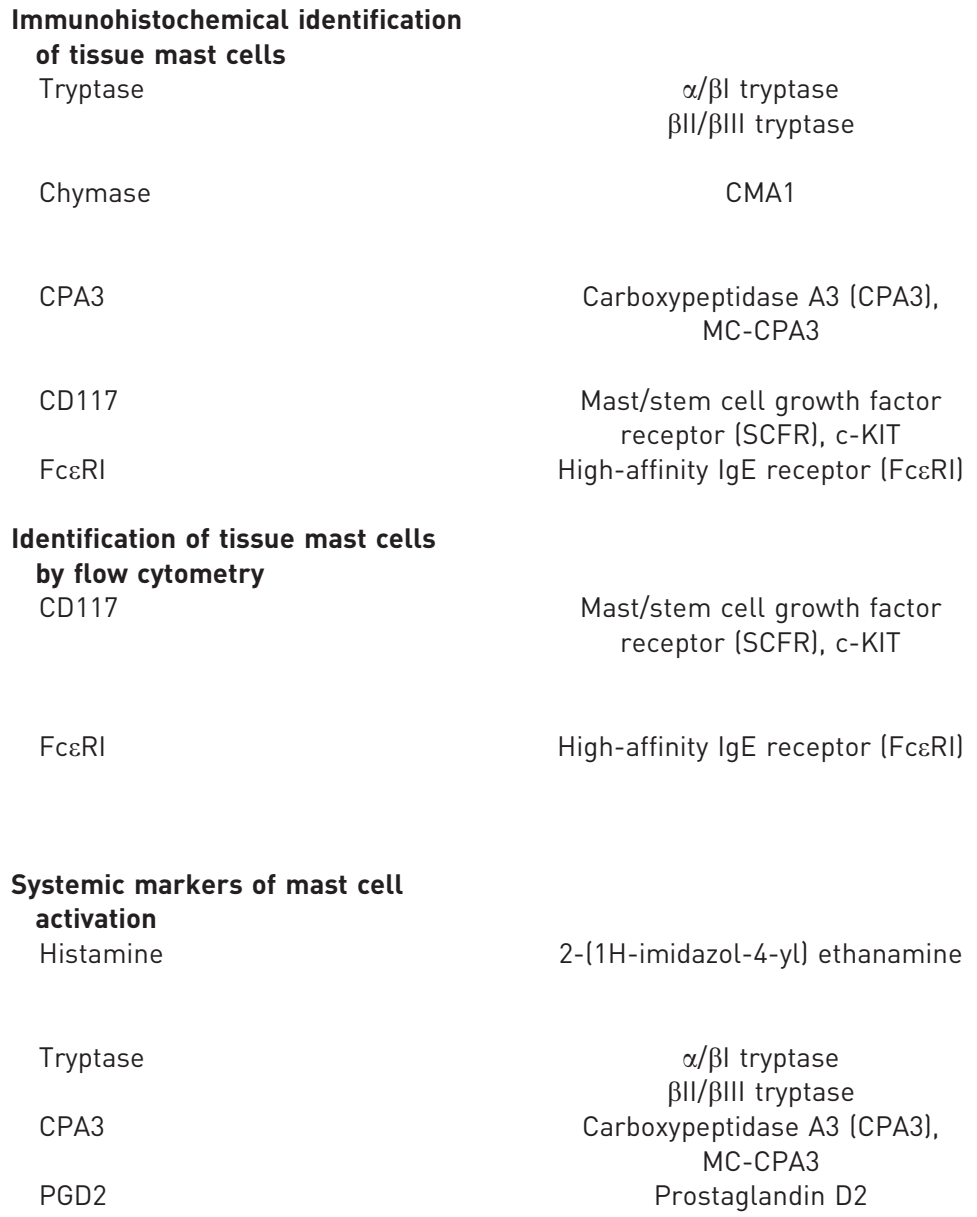

Specific pan-mast cell marker

Double IHC staining with chymase can be used to distinguish MCT and MCTC mast cells Specific MCTC marker

Double IHC staining with tryptase can be used to distinguish MCT and MCTC mast cells Mast cell specific

Primarily expressed in MCTC cells but CPA3 has also been identified in chymase-low mast cells A key, albeit nonspecific, marker for mast cells; also expressed on basophils and haematopoietic stem cells Important but nonspecific marker for mast cells; also expressed on basophils and dendritic cells

Gating of CD117-high cells with characteristic side scatter properties are commonly used to identify mast cells lapart from confounding expression on progenitor cells, invariable CD117 expression is also present on basophils)

FceRI positivity combined with CD117 expression and characteristic side scatter properties requires awareness of the low FceRI expression on human alveolar mast cells and confounding expression on basophils and dendritic cells

Limited use in respiratory diseases due to short-lived increase in plasma, also produced by basophils, nerves and enterochromaffin-like cells in the gut

Mast cell specific but limited assay sensitivity limits its use outside systemic anaphylactic reactions or mastocytosis

Mast cell specific, higher sensitivity than tryptase but CPA3 do not reflect the activity of MCT cells

Not mast cell specific, but mast cells contribute to the vast majority of plasma PGD2

Robust and sensitive detection of the PGD2 metabolite 9a11b-PGF2 has been measured in asthma by GC-NICIMS

IHC: immunohistochemistry; MCT: tryptase-positive, chymase-negative; MCTC: tryptase-positive, chymase-positive; GC-NICIMS: gas chromatography-negative ion chemical ionisation-mass spectrometry. 
enter the clinic were the mast cell-stabilisation chromones and antihistamines. Histamine exerts its effects via four receptors ( $\mathrm{H} 1$ to $\mathrm{H} 4)$. The strategy for intervention has been focused on the $\mathrm{H} 1$ receptor. To date more than $40 \mathrm{H} 1$ receptor antagonists have been approved for clinical use. Although histamine can also be produced by basophils, it can be assumed that mast cells represent the main sources of histamine. Consequently, the clinical efficacy of antihistamines in allergic rhinoconjunctivitis is a strong indication that mast cells do have a critical pathogenic role in the upper airways. However, considering the proposed key role for histamine in allergy in general, it is still a mystery why similar efficacy cannot be achieved in allergic asthma. Potential explanations could be differences in end organ receptor function, less optimal drug dosing in small bronchi and bronchioles, or simply the more complex immunopathology in asthma. Mast cell stabilisers, for example cromolyn sodium and nedocromil sodium, have been used for decades although it was only recently shown that the membrane stabilising effect was mediated with the G protein-coupled receptor 35. Again, whereas acceptable clinical efficacy can be reached in allergic rhinitis, the effect in asthma has been much more uncertain and unpredictable.

Another therapy that has a significant bearing on mast cells is anti-IgE treatment. The pioneering drug in this class, the neutralising anti-IgE monoclonal antibody omalizumab, has been shown to reduce both inflammatory parameters, as well as patient-related outcomes (e.g. symptom scores and quality of life) in asthmatics. However, a caveat with this treatment is its unpredictable efficacy; while some patients experience dramatic improvement, the majority of treated patients display little or no signs of clinical improvement. Nonetheless, anti-IgE therapy represents an important contribution to the treatment of allergic airway diseases. As for other biologics, the clinical experience with anti-IgE therapy has also spurred the well-needed search for improved biomarkers and stratified treatment strategies in diseases such as asthma. With mast cells being the major producers of leukotrienes and prostaglandins (e.g. prostaglandin (PG)D2), the clinical efficacy of anti-leukotrienes in asthma and the emerging PGD2 receptor 1 antagonists can be interpreted as a further strong indication of a significant mast cell role, at least in allergic airway disease. Similar clinical indications of mast cell roles in nonallergic respiratory conditions are still scarce. In this regard, IL-17-mediated immunity is an interesting field since mast cells have been put forward as the main IL-17 producers in inflammatory joint and skin diseases (the situation is probably similar in the respiratory tract). Several IL-17 targeting therapies are in late stage clinical development and whether these will be useful in nonallergic respiratory inflammation remains to be explored. Mast cells have been implicated in lung fibrosis $[8,9]$ and this represents another promising area for mast cell intervention. However, although promising results have been produced in preclinical models with drugs targeting chymase or mast cell-derived growth factors [61, 62], clinical data are still lacking.

\section{Conclusion}

With an ever-present abundance and vast multifunctional capacity, mast cells are most probably involved in most, if not all, types of inflammatory conditions of the respiratory tract. Currently there is rapid progression in the delicate matter of dissecting out and defining the relative importance of the good and bad roles of mast cells in relevant clinical settings. Together with a better understanding of mast cell heterogeneity at the microenvironmental level, this will most likely lead to new treatment strategies for both allergic and nonallergic respiratory diseases.

\section{References}

Taylor ML, Metcalfe DD. Mast cells in allergy and host defense. Allergy Asthma Proc 2001; 22: 115-119. Wernersson S, Pejler G. Mast cell secretory granules: armed for battle. Nat Rev Immunol 2014; 14: 478-494. Metz M, Grimbaldeston MA, Nakae S, et al. Mast cells in the promotion and limitation of chronic inflammation. Immunol Rev 2007; 217: 304-328.

Metcalfe DD, Baram D, Mekori YA. Mast cells. Physiol Rev 1997; 77: 1033-1079.

5 Bradding P, Walls AF, Holgate ST. The role of the mast cell in the pathophysiology of asthma. J Allergy Clin Immunol 2006; 117: 1277-1284.

6 Andersson CK, Mori M, Bjermer L, et al. Alterations in lung mast cell populations in patients with chronic obstructive pulmonary disease. Am J Respir Crit Care Med 2010; 181: 206-217.

7 Ballarin A, Bazzan E, Zenteno RH, et al. Mast cell infiltration discriminates between histopathological phenotypes of chronic obstructive pulmonary disease. Am J Respir Crit Care Med 2012; 186: 233-239.

8 Overed-Sayer C, Rapley L, Mustelin T, et al. Are mast cells instrumental for fibrotic diseases? Front Pharmacol 2013; 4: 174 .

9 Andersson CK, Andersson-Sjoland A, Mori M, et al. Activated MCTC mast cells infiltrate diseased lung areas in cystic fibrosis and idiopathic pulmonary fibrosis. Respir Res 2011; 12: 139.

10 Cha SI, Chang CS, Kim EK, et al. Lung mast cell density defines a subpopulation of patients with idiopathic pulmonary fibrosis. Histopathology 2012; 61: 98-106.

11 Wygrecka M, Dahal BK, Kosanovic D, et al. Mast cells and fibroblasts work in concert to aggravate pulmonary fibrosis: role of transmembrane SCF and the PAR-2/PKC-alpha/Raf-1/p44/42 signaling pathway. Am J Pathol 2013; 182: 2094-2108.

12 Abraham SN, St John AL. Mast cell-orchestrated immunity to pathogens. Nat Rev Immunol 2010; 10: 440-452. 

infection is mediated by active infection and RIG-I signaling. J Immunol 2013; 190: 4676-4684.

Galli SJ, Tsai M. IgE and mast cells in allergic disease. Nat Med 2012; 18: 693-704.

15 Persson CG, Erjefalt JS, Greiff L, et al. Plasma-derived proteins in airway defence, disease and repair of epithelial injury. Eur Respir J 1998; 11: 958-970.

16 McDonald DM, Thurston G, Baluk P. Endothelial gaps as sites for plasma leakage in inflammation. Microcirculation 1999; 6: 7-22.

17 Lundequist A, Pejler G. Biological implications of preformed mast cell mediators. Cell Mol Life Sci 2011; 68: 965-975. Metz M, Maurer M. Mast cells - key effector cells in immune responses. Trends Immunol 2007; 28 : $234-241$.

9 Holgate ST, Salvi SS. Mast cell tryptase as a proinflammatory mediator in late-phase asthmatic response. Curr Allergy Asthma Rep 2002; 2: 105-106.

20 Galli SJ, Kalesnikoff J, Grimbaldeston MA, et al. Mast cells as "tunable” effector and immunoregulatory cells: recent advances. Annu Rev Immunol 2005; 23: 749-786.

21 St John AL, Abraham SN. Innate immunity and its regulation by mast cells. J Immunol 2013; 190: 4458-4463.

22 Hofmann AM, Abraham SN. New roles for mast cells in pathogen defense and allergic disease. Discov Med 2010; 9: 79-83.

23 Galli SJ, Maurer M, Lantz CS. Mast cells as sentinels of innate immunity. Curr Opin Immunol 1999; 11 : 53-59.

24 Shikhagaie MM, Andersson CK, Mori M, et al. Mapping of TLR5 and TLR7 in central and distal human airways and identification of reduced TLR expression in severe asthma. Clin Exp Allergy 2014; 44: $184-196$.

25 Sethi S. Infection as a comorbidity of COPD. Eur Respir J 2010; 35: 1209-1215.

26 Jackson DJ, Sykes A, Mallia P, et al. Asthma exacerbations: origin, effect, and prevention. J Allergy Clin Immunol 2011; 128: 1165-1174.

27 Edwards MR, Bartlett NW, Hussell T, et al. The microbiology of asthma. Nat Rev Microbiol 2012; 10: 459-471.

28 Ishizuka T, Okayama Y, Kobayashi H, et al. Interleukin-10 is localized to and released by human lung mast cells. Clin Exp Allergy 1999; 29: 1424-1432.

29 Piliponsky AM, Chen CC, Rios EJ, et al. The chymase mouse mast cell protease 4 degrades TNF, limits inflammation, and promotes survival in a model of sepsis. Am J Pathol 2012; 181: 875-886.

30 Waern I, Karlsson I, Thorpe M, et al. Mast cells limit extracellular levels of IL-13 via a serglycin proteoglycan-serine protease axis. Biol Chem 2012; 393: 1555-1567.

31 Xue L, Salimi M, Panse I, et al. Prostaglandin D2 activates group 2 innate lymphoid cells through chemoattractant receptor-homologous molecule expressed on TH2 cells. J Allergy Clin Immunol 2014; 133: 1184-1194.

32 Enerback L. Mast cells in rat gastrointestinal mucosa. I. Effects of fixation. Acta Pathol Microbiol Scand 1966; 66: 289-302.

Irani AM, Schwartz LB. Mast cell heterogeneity. Clin Exp Allergy 1989; 19: 143-155.

Lee TD, Swieter M, Bienenstock J, et al. Heterogeneity in mast cell populations. Clin Immunol Rev 1985; 4: 143-199. Moon TC, St Laurent CD, Morris KE, et al. Advances in mast cell biology: new understanding of heterogeneity and function. Mucosal Immunol 2010; 3: 111-128.

36 Brightling CE, Bradding P, Symon FA, et al. Mast-cell infiltration of airway smooth muscle in asthma. $N$ Engl J Med 2002; 346: 1699-1705.

37 Balzar S, Chu HW, Strand M, et al. Relationship of small airway chymase-positive mast cells and lung function in severe asthma. Am J Respir Crit Care Med 2005; 171: 431-439.

38 Andersson CK, Bergqvist A, Mori M, et al. Mast cell-associated alveolar inflammation in patients with atopic uncontrolled asthma. J Allergy Clin Immunol 2011; 127: 905-912.

39 Andersson CK, Tufvesson E, Aronsson D, et al. Alveolar mast cells shift to an FceRI-expressing phenotype in mild atopic asthma: a novel feature in allergic asthma pathology. Allergy 2011; 66: 1590-1597.

40 Kawanami O, Ferrans VJ, Fulmer JD, et al. Ultrastructure of pulmonary mast cells in patients with fibrotic lung disorders. Lab Invest 1979; 40: 717-734.

41 Andersson CK, Mori M, Bjermer L, et al. Novel site-specific mast cell subpopulations in the human lung. Thorax 2009; 64: 297-305.

42 Bradding P. Human lung mast cell heterogeneity. Thorax 2009; 64: 278-280.

43 Fox B, Bull TB, Guz A. Mast cells in the human alveolar wall: an electronmicroscopic study. J Clin Pathology 1981; 34: 1333-1342.

44 Warton A, Papadimitriou JM, Goldie RG, et al. An ultrastructural study of mast cells in the alveolar wall of normal and asthmatic lung. Aust J Exp Biol Med Sci 1986; 64: 435-444.

45 Wenzel SE. Asthma phenotypes: the evolution from clinical to molecular approaches. Nat Med 2012; 18: 716-725. Holgate ST. Stratified approaches to the treatment of asthma. Br J Clin Pharmacol 2013; 76: $277-291$.

Fajt ML, Wenzel SE. Biologic therapy in asthma: entering the new age of personalized medicine. J Asthma 2014; 13: 1-8. Haldar P, Pavord ID, Shaw DE, et al. Cluster analysis and clinical asthma phenotypes. Am J Respir Crit Care Med 2008; 178: 218-224.

49 Bergqvist A, Andersson CK, Hoffmann HJ, et al. Marked epithelial cell pathology and leukocyte paucity in persistently symptomatic severe asthma. Am J Respir Crit Care Med 2013; 188: 1475-1477.

50 Kraft M, Djukanovic R, Wilson S, et al. Alveolar tissue inflammation in asthma. Am J Respir Crit Care Med 1996; 154: 1505-1510.

51 Sutherland ER, Martin RJ. Distal lung inflammation in asthma. Ann Allergy Asthma Immunol 2002; 89: 119-124.

52 de Magalhaes Simoes S, dos Santos MA, da Silva Oliveira M, et al. Inflammatory cell mapping of the respiratory tract in fatal asthma. Clin Exp Allergy 2005; 35: 602-611.

53 Hauber HP, Gotfried M, Newman K, et al. Effect of HFA-flunisolide on peripheral lung inflammation in asthma. J Allergy Clin Immunol 2003; 112: 58-63.

54 Nihlberg K, Andersson-Sjoland A, Tufvesson E, et al. Altered matrix production in the distal airways of individuals with asthma. Thorax 2010; 65: 670-676.

55 Bergqvist A, Andersson CK, Mori M, et al. Alveolar T-helper type 2 immunity in atopic asthma is associated with poor clinical control. Clin Sci 2014 [In press DOI: 10.1042/CS20140309].

56 Kiyokawa H, Matsumoto H, Nakaji H, et al. Centrilobular opacities in the asthmatic lung successfully treated with inhaled ciclesonide and tiotropium: with assessment of alveolar nitric oxide levels. Allergol Int 2011; 60: 381-385. 
57 Bafadhel M, McKenna S, Terry S, et al. Acute exacerbations of chronic obstructive pulmonary disease: identification of biologic clusters and their biomarkers. Am J Respir Crit Care Med 2011; 184: 662-671.

58 Kosanovic D, Dahal BK, Wygrecka M, et al. Mast cell chymase: an indispensable instrument in the pathological symphony of idiopathic pulmonary fibrosis? Histol Histopathol 2013; 28: 691-699.

59 Kalesnikoff J, Galli SJ. New developments in mast cell biology. Nat Immunol 2008; 9: 1215-1223.

60 Metcalfe DD, Peavy RD, Gilfillan AM. Mechanisms of mast cell signaling in anaphylaxis. J Allergy Clin Immunol 2009; 124: 639-646.

61 Harvima IT, Levi-Schaffer F, Draber P, et al. Molecular targets on mast cells and basophils for novel therapies. J Allergy Clin Immunol 2014 [In press DOI 10.1016/j.jaci.2014.03.007].

62 Reber LL, Frossard N. Targeting mast cells in inflammatory diseases. Pharmacol Ther 2014; 142: 416-435. 